\section{Методы повышения износостойкости динамического лункообразователя для посадки лесных культур}

Эгипти А.Э!

Петрозаводский государственный университет

Предлагается методика выбора конструкторскотехнологических решений для повышения долговечности лесохозяйственных машин.

Ключевые слова: лесовосстановление, лункообразователь, рабочий орган, почва, испьтания.

Для механизации лесовосстановления на вырубках созданы лункообразователи Л-2, Л-2У, агрегатируемые с тракторами, оборудованными задним валом отбора мощности: МТЗ-82, ЛХТ-55, ЛХТ-100.

Лункообразователь предназначен для одновременного приготовления двух рядов посадочных лунок с целью создания лесных культур саженцами с открытой и закрытой корневой системой. Используется на вырубках с любым количеством пней и каменистыми включениями. Раскорчевка пней и предварительная подготовка почвы не требуется [1].

При непрерывном движении лункообразователь ударным способом подготавливает два ряда лунок, образуя на краю каждой лунки комок почвы, используемый для заделки корней саженцев. Почвенный покров сохраняется.

Рабочие органы лункообразователя конструктивно просты, не теряют работоспособности при ударах о камни. Специфичность функционирования рабочих органов состоит в периодическом ударном контакте с почвой при сопутствующем абразивном износе во время формирования лунки.

Возможность возникновения отказов при работе машины складывается из совокупности эксплуатационных, конструкторских и технологических факторов всей машины в целом, и агрегатов и деталей в частности. По характерным признакам выполняемых операций наибольшая вероятность отказа присуща рабочим органам. Исследовались эксплуатационные свойства рабочих органов (игл) различных вариантов конструкции и типа материала, технологии изготовления и поверхностного упрочнения.

Учитывая экономический фактор при выборе типа материала, ставилась задача изготовления цельной иглы с использованием дефицитных легированных сталей (невосстанавливаемый объект) или рядовых углеродистых конструкционных сталей в варианте составной иглы (восстанавливаемый объект).

\footnotetext{
I Автор - дочент кафедры технологии металлов и ремонта

(c) А.Э.Эгипти, 1996
}

Составной рабочий орган лункообразователя (рис.1) изготовлен методом фрезерования из сортового проката в виде разъемной иглы клиновидной формы массой 12,2 кг. Включает в себя тело иглы 1 и съемный наконечник 2, который присоединительным плоским конусом 3 вставляется в ответный конический паз тела иглы. Когда игла собрана, в отверстия 4,5 вставляется фиксатор, предотвращающий выпадение наконечника. В момент внедрения иглы в почву упор 6 ограничивает глубину формирующейся лунки. Крепление иглы к качающемуся рычагу лункообразователя осуществляется постановкой пальца: в отверстие 7 щеки рабочего органа. Проушина 8 предназначена для крепления фиксатора угла поворота иглы относительно оси качания рычага так, чтобы угол внедрения иглы в почву находился в диапазоне 75-850. При этом условии гарантируется образование комка почвы в виде призмы треугольного сечения для заделки корней растения.

Тело иглы изготовлено из стали марки Ст3сп, для съемных наконечников выбраны стали марок У8, 40X, 5ХНМ, термически упрочненные.

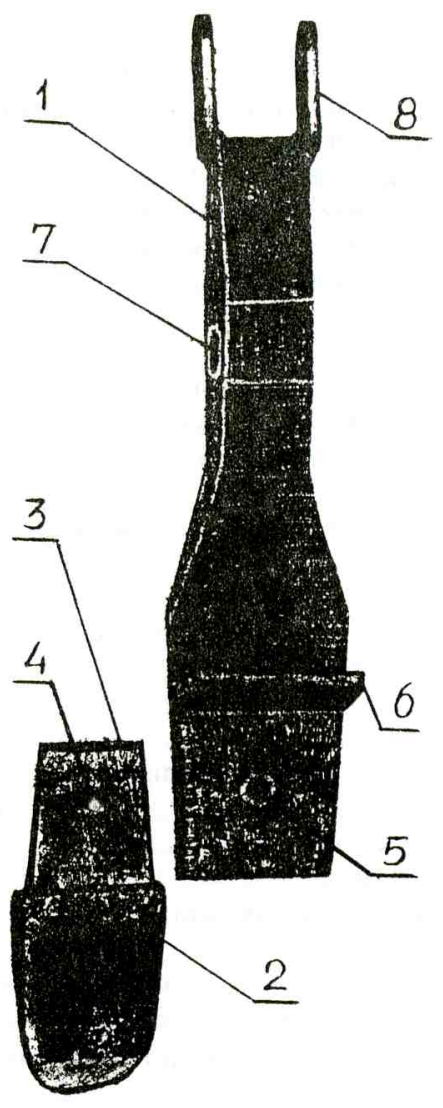

Рис. 1. Составной рабочий орган лункообразователя: 1 - тело иглы, 2 - сменный наконечник, 3 -присоединительный конус, 4,5 - отверстия для фиксации наконечника, 6 - упор ограничения внедрения иглы в почву, 7 - отверстие для пальца, 8 - вилка регуляора поворота. 
В первом варианте цельной иглы отрабатывался эффект самозатачиваемости двухслойного материала. характерный для рабочих органов почвообрабатывающих орудий непрерывного действия типа лемехов плугов, рыхлительных лап и т.п. Игла изготовлена из стали марки СтЗсп с наплавкой по задней поверхности рабочей части износоустойчивого слоя толщиной $3 \pm 0.5$ мм. твердостью НRСэ $55 \ldots 60$.

Вторая цельная игла изготовлена из прутка стали марки 40X по технологии свободной ковки для придания геометрической формы и создания внутренней волокнистой структуры. Способом термического упрочнения накалываюшей зоны иглы избрана индукционная закалка токами высокой частоты в одновитковом индукторе. Повышение механических свойств осуществлено за счет создания остаточных напряжений сжатия в наружном слое при вязкой сердцевине. Минимизация размеров кристаллов мартенсита достигается за счет увеличения степени перегрева с последуюшим охлаждением в масляной среде и самоотпуском. Зона термической обработки распространяется на 0.08 м от вершины иглы вдоль оси симметрии с постепенным изменением твердости от 55 до $20 \mathrm{HRCэ}$

Конструкторско-технологическое решение для третьего варианта цельной иглы принято в виде литья в разовые песчано-глинистые формы стали марки $110 Г 13 Л$, предназначенной для эксплуатации в режиме ударных нагрузок. Отливка подвергается термическому воздействию для снятия внутренних напряжений и минимальной механической обработке отверстия в щеке иглы.

Эксплуатация лункообразователя в период производственных испытаний производилась на характерных вырубках региона Карелии

\section{Условия проведения испьтаний}

1. Количество пней на вырубке, шт./ га..............1100

2. Сплошное залегание камней на глубине менее 0.15 м от площади вырубки, "\% ................................... 72

3. Тип почвы..........суглинок средний с оподзоленным

............................................. верхним слоем

4. Тип лесорастительных условий ....................ельник

.............................................. черничник

5. Глубина лунок, м ........................................... 0,22

6. Шаг посадки, м ...................................... 0,48-1,18

7. Скорость движения агрегата, км/ч................ 1-2,5

Согласно лесотехническим требованиям количество лунок на гектар возобновляемой площади, отнесенное к рабочему органу, составляет величину $1,62 \cdot 10^{3}$.

В период испытаний оценивалась работоспособность игл и замер величин износа по передней и задней поверхностям.

Подтверждена работоспособность сос-тавной игль с набором сменных наконечников. Выявлена необходимость доработки иглы, заключающаяся в изменении способа фиксации и съема наконечников.
Цельная игла с наплавкой твердым сплавом, на которой отрабатывался эффект самозатачиваемости, снята с эксплуатации вследствие расплющивания вершины иглы и потери работоспособности (рис.2а.б)

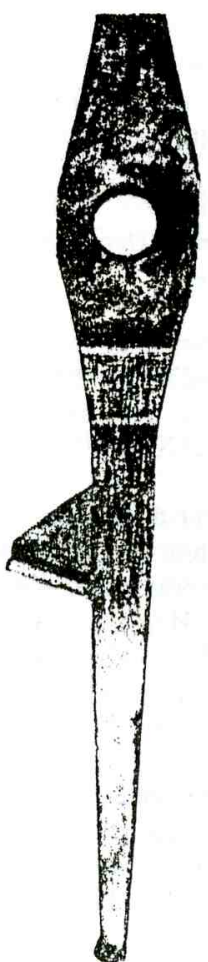

a.

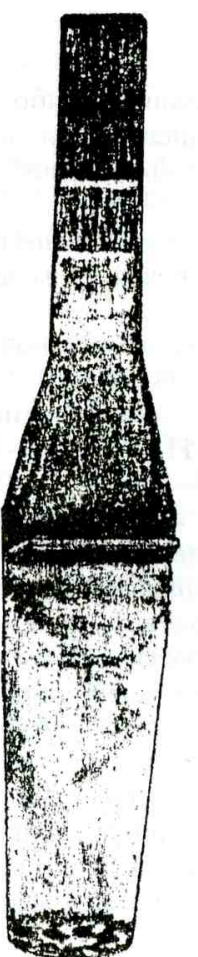

$\delta$.

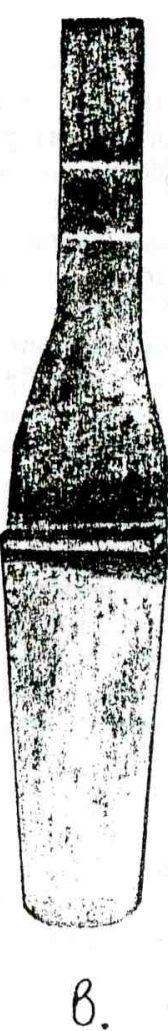

B.
Рис.2. Рабочие органы лункообразователя после производственных испытаний: а.б-изменение геометрической формы рабочей части наплавленной иглы; в - то же кованой иглы.

Вид кованой иглы после наработки 120 га представлен на рис.2в. Изнашивание накалывающей части иглы носит деградационный характер, когда вследствие абразивного воздействии почвы и ударных нагрузок происходит изменение геометрии рабочей зоны. Уменьшается длина рабочей части, радиусы закругления, измеренные по передней поверхности, составляют одну треть от ширины накалывающей зоны. Радиус закругления при вершине иглы изменяется от начального, равного 1, до 5 мм после приработки. Интенсивность изнашивания рабочей части 0,22 мм/га.

В период испытаний у литых игл из износоустойчивой стали наблюдались производственные дефекты типа сквозных трещин, возникшие в результате нарушения установленного процесса изготовления. По 
сравнению с коваными литые иглы обладали более высокой износостойкостью, интенсивность изнашивания составила 0,07 мм/га, радиус при вершине после приработки 4,5 мм.

Выявленные после приработки радиусы закругления рабочей части заложены в конструкторские размеры иглы.

По результатам испытаний рекомендованы к изготовлению рабочие органы из литейной износоустойчивой стали марки 110Г13Л.
Для обеспечения качества изготовления лункообразователей вместе с заводским контролем необходим авторский надзор.

Требуется продолжить исследование надежости рабочих органов и обосновать количество запасных игл, поставляемых с лункообразователем.

\section{ЛИТЕРАТУРА}

1. Цыпук А.М.,Эгипти А.Э.,Соколов А.И. Создание лесных культур посадкой под лункообразователь Л-2 // Лесное хозяйство. 1990. N11. с.43-45. 